\title{
Application of Climate Impact Metrics to Civil Tiltrotor Design
}

\author{
Carl Russell ${ }^{1}$ and Wayne Johnson ${ }^{2}$ \\ NASA Ames Research Center, Moffett Field, CA, 94035
}

\begin{abstract}
Multiple metrics are applied to the design of a large civil tiltrotor, integrating minimum cost and minimum environmental impact. The design mission is passenger transport with similar range and capacity to a regional jet. Separate aircraft designs are generated for minimum empty weight, fuel burn, and environmental impact. A metric specifically developed for the design of aircraft is employed to evaluate emissions. The designs are generated using the NDARC rotorcraft sizing code, and rotor analysis is performed with the CAMRAD II aeromechanics code. Design and mission parameters such as wing loading, disk loading, and cruise altitude are varied to minimize both cost and environmental impact metrics. This paper presents the results of these parametric sweeps as well as the final aircraft designs.
\end{abstract}

\section{Nomenclature}

Acronym
AIC
ATR
CAMRAD
CTR
EI
EU ETS
HOGE
ISA
NDARC
OEI
RF
Symbols
$C_{W}$
NO
$r$
$t$
$V_{b r}$
$\sigma$

\author{
Aviation Induced Cloudiness \\ Average Temperature Response \\ Comprehensive Analytical Model of Rotorcraft Aerodynamics and Dynamics \\ Civil Tiltrotor \\ Emissions Index \\ European Union Emissions Trading Scheme \\ Hover Out of Ground Effect \\ International Standard Atmosphere \\ NASA Design and Analysis of Rotorcraft \\ One Engine Inoperative \\ Radiative Forcing
}

Rotor weight coefficient
Oxides of nitrogen $\left(\mathrm{NO}\right.$ and $\left.\mathrm{NO}_{2}\right)$
Devaluation rate
Time, years
Speed for maximum range
Rotor solidity

\section{Introduction}

$\mathrm{R}$ OTORCRAFT and other V/STOL aircraft have the potential to increase throughput in the National Airspace System (NAS) without requiring significant additional infrastructure at airports; however, air pollution is becoming increasingly regulated in industrialized nations, so new rotary-wing aircraft will need to be designed for minimal environmental impact. ${ }^{1,2}$ In Europe, total $\mathrm{CO}_{2}$ emissions by airlines were capped in the year 2012, with other emissions likely to follow. No such regulation has been enacted in the US, but may be in the future. If aircraft operators are limited in the amount of emissions they can legally produce, they will require designs that are not only

\footnotetext{
${ }^{1}$ Aerospace Engineer, Aeromechanics Branch, M/S 243-12, Member AIAA

${ }^{2}$ Aerospace Engineer, Aeromechanics Branch, M/S 243-12, Fellow AIAA
} 
efficient in terms of traditional metrics such as fuel burn and maintenance costs, but are also environmentally friendly.

A major conclusion of Ref. 2 was that replacing a significant portion of the regional jet traffic in the NAS with civil tiltrotors (CTR) could reduce future air traffic delays by more than 50 percent. Several NASA studies in the past decade have examined multiple rotorcraft configurations for large civil transport missions. These studies have largely concluded that a CTR is the best rotorcraft option for transporting payloads of approximately 100 passengers over ranges of around $1,000 \mathrm{~nm}^{3,4}$ Refinements to CTR designs have been the subject of many past and current studies. $^{5,6}$

Environmental performance, particularly from an emissions standpoint, has been largely overlooked up to this point in rotorcraft design. Worldwide, aviation accounts for approximately $5 \%$ of all anthropogenic sources of radiative forcing, a measure of the atmospheric effects of various pollutants. ${ }^{7}$ If tiltrotors are to become a large part of the civil aviation fleet, they have the potential to make a substantial contribution to aviation's overall climate impact. There are multiple existing metrics that can be used to evaluate the effects of combustion emissions on the environment. Metrics specifically targeted at evaluating aircraft emissions are also becoming available. ${ }^{8,9}$

The purpose of the current study is to evaluate the environmental performance of a large civil tiltrotor. In addition to environmental performance, the aircraft are evaluated for both minimum fuel burn (generally corresponding to direct operating cost) and minimum empty weight (generally corresponding to airframe purchase cost). While future rotorcraft will likely be designed to balance operating costs, purchase costs, and environmental performance, this study will separate them in order to show the effects of designing to different metrics.

\section{Background}

\section{A. Environmental Impacts}

Designing rotorcraft for minimum environmental impact from an emissions standpoint is a fairly new area of research, though the impacts of fixed-wing aircraft have been studied for decades. ${ }^{7}$ There is significant uncertainty in many of the metrics that can be used to evaluate the effects of emissions. Figure 1 shows the cause and effect chain linking aircraft emissions to atmospheric changes and ultimately societal impacts. ${ }^{10}$ Effects near the top of the figure are relatively easy to quantify, but are difficult to link to costs in terms of social welfare and are thus not very useful for evaluating rotorcraft concepts. Effects near the bottom of the figure are much more difficult to accurately quantify, but are much more relevant from a political and social welfare standpoint. Any metric that is used to evaluate new rotorcraft concepts should balance uncertainty with relevance as much as possible.

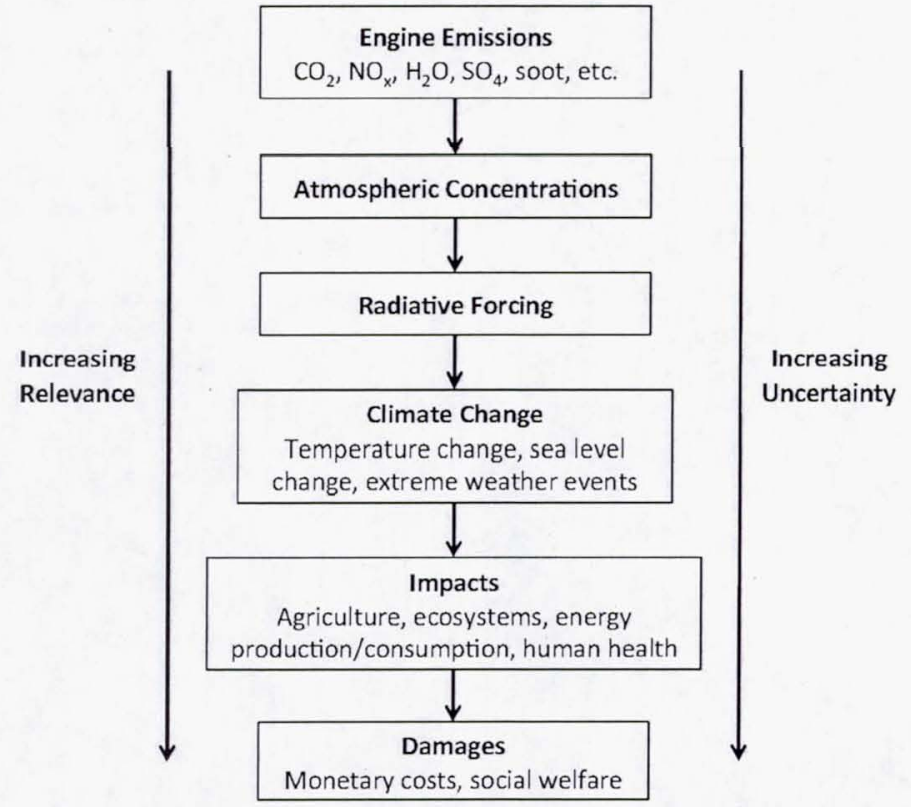

Figure 1. Cause-effect chain for climate change induced by aircraft emissions, adapted from Ref.10. 
In addition to choosing metrics that are relevant to current or future public policy and that have acceptable levels of uncertainty, it is desirable to use metrics that account for all relevant aircraft emissions, rather than a single species. Figure 2 shows the radiative forcing (RF) in the year 2000 for the primary emission species produced by aircraft. ${ }^{11} \mathrm{RF}$ is a measure of the amount of heat trapped in the atmosphere by a particular pollutant, and is expressed in terms of trapped energy per unit area. The level of scientific understanding (LOSU) for each emission species is also shown.

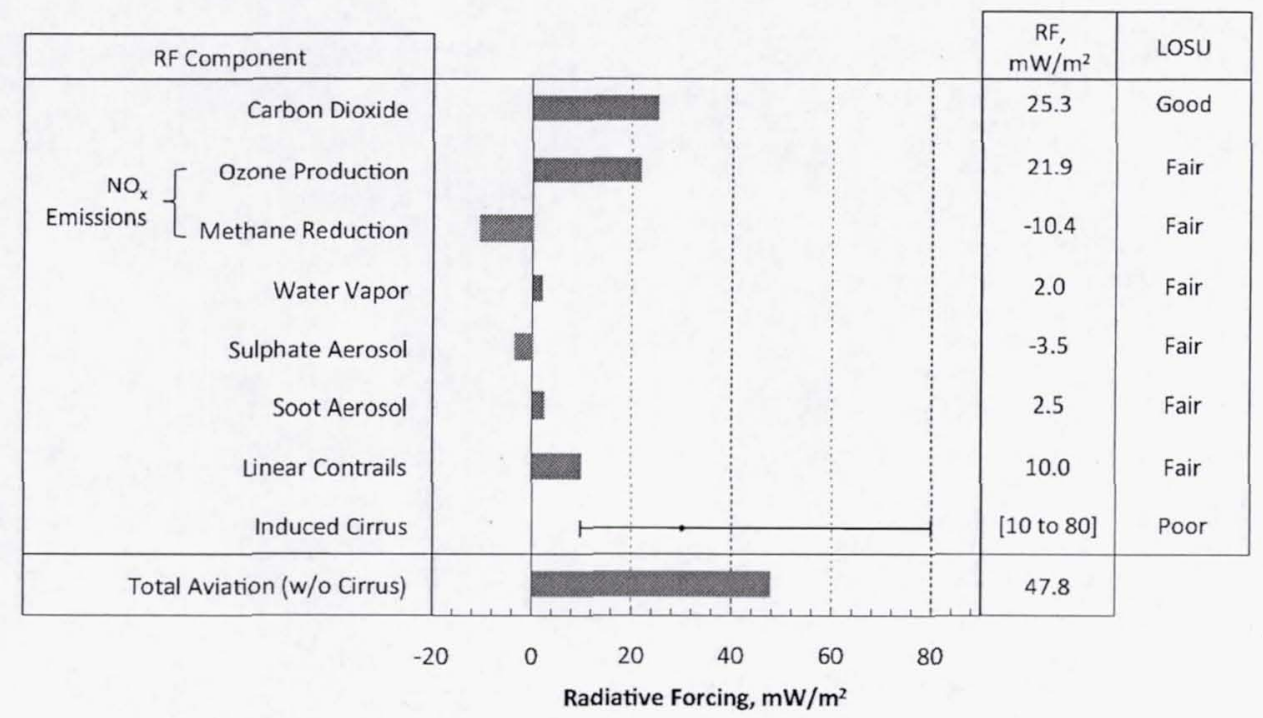

Figure 2. Components of RF due to various aircraft emission species, adapted from Ref. 11.

$\mathrm{NO}_{x}$ emissions cause changes in RF indirectly through chemical processes in the atmosphere. Increases in $\mathrm{NO}_{x}$ lead to both increases in atmospheric ozone (a warming effect), and reductions in methane (a cooling effect). ${ }^{12}$ The methane reduction has a secondary effect of reducing ozone, so there are actually three components of RF due to NOx emissions. All three are accounted for in the current study. Note that the impact of $\mathrm{NO}_{\mathrm{x}}$ emissions is similar in magnitude to that of $\mathrm{CO}_{2}$, but there is greater uncertainty in the $\mathrm{NO}_{\mathrm{x}} \mathrm{RF}$ values shown in Fig. 2. The black dot and error bars show, respectively, the best estimate and upper and lower bounds of RF due to induced cirrus reported in Ref. 11. The total RF due to aviation shown at the bottom of Fig. 2 does not include the effects of induced cirrus cloudiness, due to the low level of scientific understanding.

\section{B. Climate Impact Metrics}

Several environmental metrics were considered to measure the effects of civil tiltrotor emissions for this study. Of the available metrics, two were identified with high potential for evaluating CTR concepts. In general, both metrics are well defined and have relatively wide acceptance in industry, public policy, or academia. The current investigation uses both of them. These metrics, along with their advantages and disadvantages are described below.

\section{European Union Emissions Trading Scheme (EU ETS) Credits}

The Emissions Trading Scheme is the system in place in the European Union to curb the effects of greenhouse gas emissions on global climate change. ${ }^{13}$ Initiated in 2005 , the ETS places limits on the amount of carbon dioxide that can be produced by large polluters such as energy and industrial installations in the EU. The ETS was extended to the aviation sector in early $2012 .^{14}$

Under the ETS, each member nation has an emission cap that is used to allocate allowable carbon emissions to their industrial operators. Operators that do not use their entire allocation can sell their unused "carbon credits" on the open market, while operators exceeding their allocation must purchase credits on the market. The price of carbon credits for the current phase of the ETS has varied widely, ranging from below $€ 10 /$ tonne $\mathrm{CO}_{2}$ to over $€ 30 /$ tonne $\mathrm{CO}_{2}{ }^{15}$

The main advantage of using ETS credits as a metric for tiltrotor designs is that this metric is easy to accurately compute and tie to direct operating cost. Total fuel burn translates directly to $\mathrm{CO}_{2}$ produced, which can be used to determine the cost of operation in terms of carbon credits. Additionally, ETS credits are the only metric that can be 
tied to current aviation policy. This metric has two main disadvantages. First, the ETS only accounts for $\mathrm{CO}_{2}$, while combustion engines produce several additional types of greenhouse emissions. Plans to include additional emissions in the ETS have been drafted, but are not yet implemented. ${ }^{16}$ The second disadvantage is that volatility in the carbon trading market makes accurately predicting the future price of carbon credits difficult.

\section{Average Temperature Response (ATR)}

Average Temperature Response is a recently developed metric that specifically targets aircraft emissions. The purpose of ATR is to assess the relative performance of aircraft concepts with respect to climate change. This metric is measured in terms of global mean temperature change caused by operation of a particular aircraft. ATR can be used with a number of different climate models, but simple linear climate models are appropriate for the conceptual design of rotorcraft. ${ }^{8}$

The ATR metric is based on the radiative forcing generated by each emission species. Many climate change metrics, such as Global Warming Potentials, rely on RF, but do not specifically target emissions due to aviation. ${ }^{17}$ The total RF for all emitted pollutants is used to calculate the global temperature response. The use of an altitudesensitive climate model captures the effects of operating a particular aircraft at a multitude of operating conditions. In addition, ATR includes parameters such as usage rates and operating lifetime of the aircraft to determine the total climate impact that results from adding a particular aircraft to an operator's fleet,

The use of ATR for measuring the environmental impact of tiltrotor concepts has two main advantages. First, ATR is specifically targeted at evaluating aircraft emissions. Second, it is flexible enough to include multiple emission species and can utilize multiple climate models. A disadvantage is that unlike Global Warming Potentials and ETS credits, ATR does not yet have widespread use in either the environmental or aviation community. It is therefore difficult to link ATR directly to cost, and this study does not attempt to do so. As is the case with other RFbased metrics, computation of ATR is subject to the uncertainty of the chosen climate model, especially with respect to $\mathrm{NO}_{\mathrm{x}}$ emissions. ${ }^{18}$

\section{Aircraft Design}

This study focuses on the design of a large civil tiltrotor. The baseline design is derived from NASA's LCTR2, described in detail in Refs. 5 and 6 . The aircraft uses a high wing with two four-bladed rotors at each wingtip. Two turboshaft engines are located directly behind each of the rotors. The wing carries a cross shaft from one engine nacelle to the other so that power can be transferred equally to both rotors in the event of a single engine failure. The empennage consists of a V-tail. Rotor cyclic and collective are used for control in hover, while control surfaces on the wings and tail are used in cruise. The layout of the tiltrotor is shown in Fig. 3. The dimensions shown are constant across different design variations. Others, such as the wingspan and rotor radius, are omitted from the drawing because they are adjusted during sizing.

For the baseline design, the wing loading is $105 \mathrm{lb} / \mathrm{ft}^{2}$, and the disk loading is $14 \mathrm{lb} / \mathrm{ft}^{2}$. Maneuver requirements result in a design $C_{W} / \sigma$ of 0.151 , which, along with the disk loading and tip speed specifications, sets the rotor solidity.

The designs are required to follow the mission profile shown in Fig. 4. Cruise altitude is not specified, and is optimized as part of the design process. In addition to the mission profile below, the designs are sized to two performance requirements. OEI hover capability is required at $5,000 \mathrm{ft}$ ISA $+20^{\circ} \mathrm{C}$. Also, while the cruise speed during the design mission is the best range speed $V_{b r}$, the aircraft must be capable of flight at $300 \mathrm{kt}$ at the design cruise altitude. 

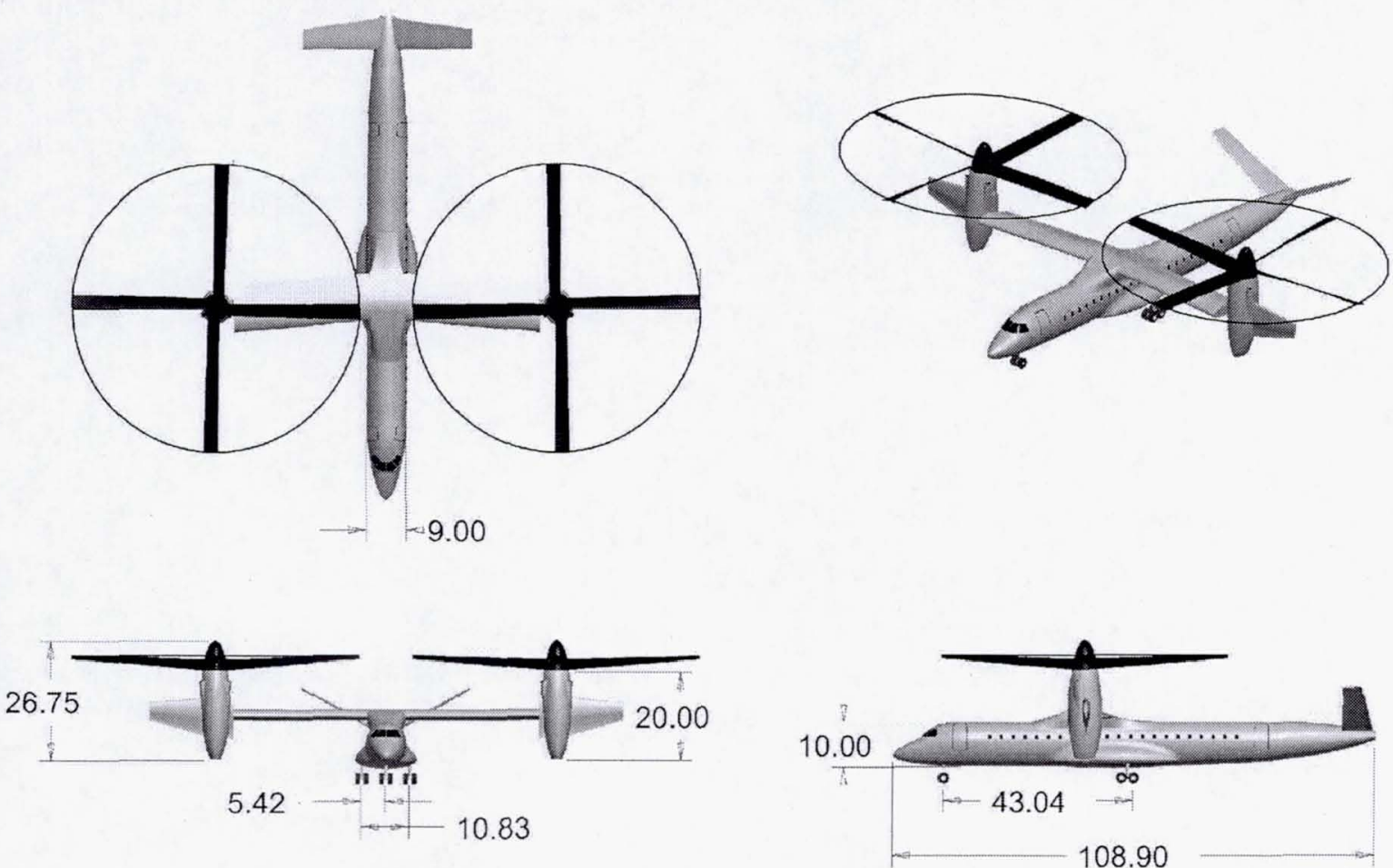

Figure 3. Illustration of the tiltrotor design (dimensions in feet)

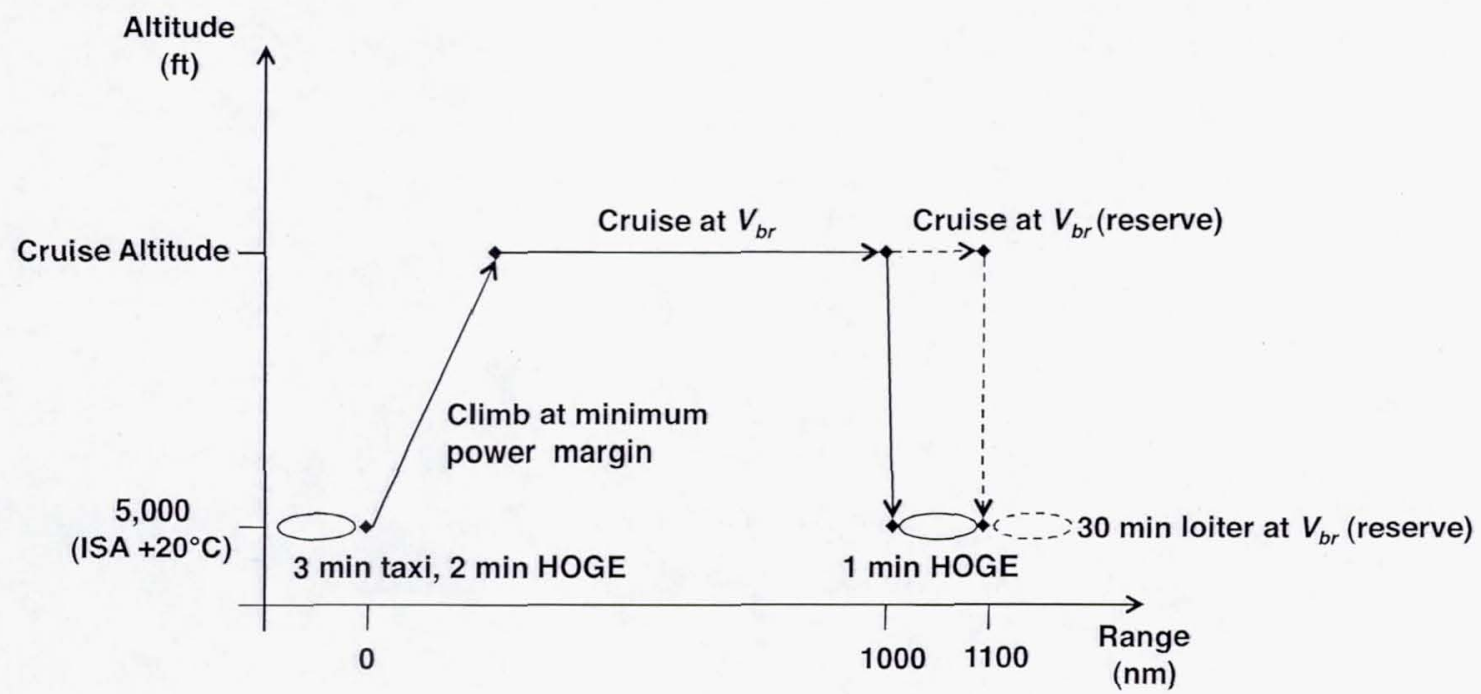

Figure 4. Design mission 


\section{Approach}

\section{A. Aircraft Design Process}

The design process used for this study is illustrated in Fig. 5. For the steps in the process, the corresponding computational tools are identified above the flowchart blocks. The first step in the process is to use the NDARC sizing code to generate the baseline design, which is described in the previous section. With the baseline determined, the next step is to develop a rotor performance model using the CAMRAD II comprehensive rotorcraft analysis software.

In previous studies, rotors with varying blade twist were analyzed to determine the optimal tradeoff between cruise and hover performance. In both Refs. 4 and 5, it was observed that for a cruise dominated mission, such as the one shown in Fig. 4, nearly all of the fuel is burned in cruise, and designing for maximum cruise efficiency alone yields a rotor very close to the optimum. By using a high rotor tip speed in hover and low tip speed in cruise, good hover performance is maintained, despite the cruise-optimized twist distribution.

To simplify the analysis for the current study, a twist following the helix swept by the rotor blade in forward flight was assumed, since this twist distribution provides a high propulsive efficiency. This twist variation is determined by only the cruise advance ratio. In this case, a forward speed of $300 \mathrm{kt}$ with a tip speed of $400 \mathrm{ft} / \mathrm{s}$ was used, resulting in an advance ratio of 1.27 . Once the baseline rotor radius, solidity, and twist distribution were selected, a performance model was generated by sweeping hover thrust, and cruise thrust and speed over the expected range of operations.

With the rotor performance model determined, aircraft characteristics are swept using NDARC to design for minimum fuel burn, empty weight, and environmental impact. NDARC does not contain a formal optimization routine, so in order to minimize a particular objective function such as fuel burn or environmental impact, parameters must be varied and a new design generated for each set of input values. There are many design parameters that can be adjusted in NDARC, so care must be taken to properly choose a small subset of them. Otherwise, the number of design cases can easily become very large. For this study, the primary variables are wing loading, disk loading, and cruise altitude.

NDARC directly outputs a large quantity of rotorcraft characteristics and performance measures, including empty weight and fuel burn, but does not yet contain a module for computing environmental metrics. A set of Matlab scripts and functions was written to parse NDARC output files and compute the ATR metric. In addition to the outputs of the sizing process, a set of engine performance maps was generated for sea-level static conditions in order to compute ATR. The details of the metric computation process are contained in a later section.

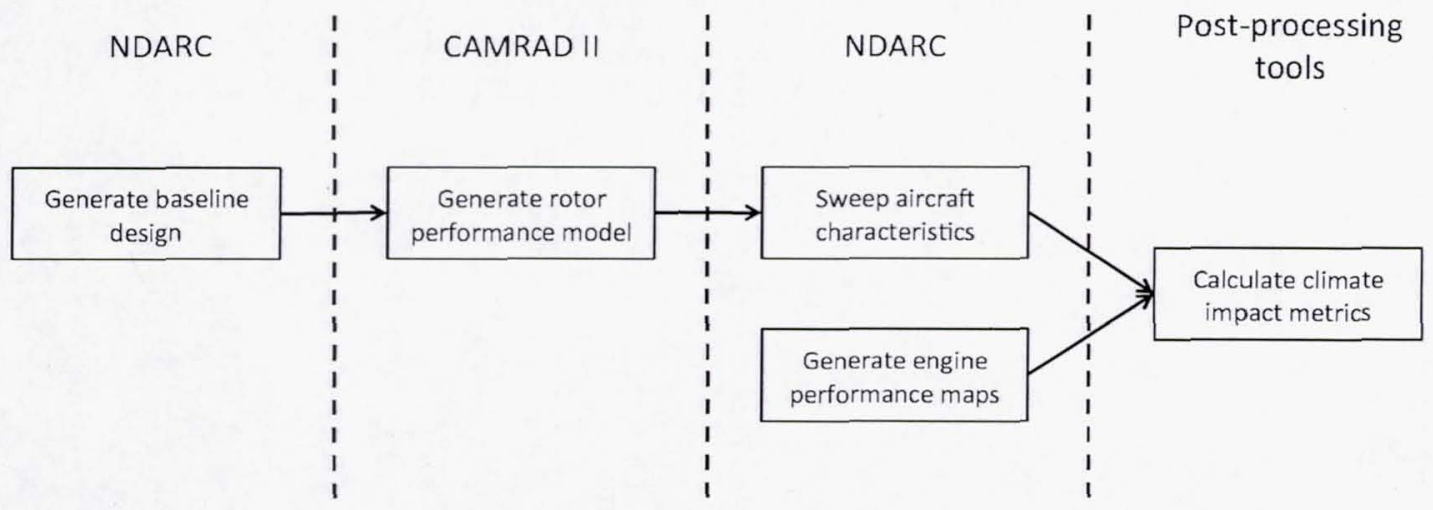

Figure 5. Design process

\section{B. Computational Tools}

\section{Sizing}

All of the sizing and design tasks were carried out using NASA's rotorcraft design code NDARC. NDARC is a conceptual/preliminary design and analysis code for rapidly sizing and conducting performance analysis of new rotorcraft concepts. ${ }^{19,20,21}$ NDARC has a modular code base, facilitating its extension to new concepts and the implementation of new computational procedures. By using simplified models to represent major rotorcraft subsystems, such as engines and rotors, NDARC can produce multiple rotorcraft designs quickly without requiring 
repeated runs of time-intensive engine cycle or rotor performance analyses. NDARC version 1.6 was used in this design activity.

During the sizing process, point condition and mission performance are calculated and the aircraft is resized both geometrically and mechanically until the convergence criteria are met. A typical NDARC run consists of a sizing task, followed by off-design performance analysis.

The outputs of the NDARC engine model were used extensively for this study. NDARC implements the Referred Parameter Turboshaft Engine Model (RPTEM), described in Ref. 19. This model is based on curve fits of engine performance data for both existing and projected engines. These curve fits can be scaled to the required engine size to represent a notional engine.

\section{Comprehensive Analysis}

For calibration of the NDARC rotor performance model, a baseline rotor was analyzed in both cruise and hover conditions using the comprehensive rotorcraft analysis CAMRAD II. ${ }^{22}$ CAMRAD II is an aeromechanics analysis of rotorcraft that incorporates a combination of advanced technologies, including multibody dynamics, nonlinear finite elements, and rotorcraft aerodynamics. CAMRAD II finds the equilibrium solution for a steady state operating condition, and then produces the solution for performance, loads, and vibration. CAMRAD II has undergone extensive correlation of performance and loads measurements on rotorcraft. ${ }^{23-30}$

For this study, rotor performance analysis in CAMRAD II considered a single rotor. The calculations for calibration of the sizing code rotor model considered an isolated rotor, without interference from other components of the tiltrotor, such as the wing or fuselage. Rotor performance was calculated using non-uniform inflow free wake geometry for both hover and high speed cruise. Airfoil characteristics were obtained from tables representing advanced technology airfoils. In hover, rotor thrust was varied from zero to well above the expected takeoff thrust of the rotor. In cruise, the pitch, thrust, and forward velocity were varied through the expected envelope of operations. The induced and profile power calculated by CAMRAD II were then used to calibrate the equations used by the NDARC rotor performance model.

\section{Performance Measures}

Two types of performance metrics were used for this study: cost oriented and emissions oriented. Airlines or other operators will likely be primarily concerned with both airframe purchase price and operational costs. For this study, empty weight and fuel burn were used in lieu of a monetary cost metric. Initial purchase price of aircraft tends to correlate well with empty weight. ${ }^{31}$ Fuel costs have been driven up by global crude oil prices in recent years and now comprise approximately half of direct operating cost. ${ }^{32}$ For this reason, fuel burn is a good indication of the cost to operate a particular design.

Emissions were measured using both ETS credits and the Average Temperature Response metric described in the Background section of this paper. A thorough description of the method for calculating ATR is contained in Ref. 8 , and the current study closely followed the process outlined therein. ATR expresses the environmental impact of a particular aircraft design in terms of the integrated global temperature change that would result from operation of the aircraft for a given amount of time. The general form of ATR is given in Eq. 1.

$$
A T R_{H}=\frac{1}{H} \int_{0}^{\infty} \Delta T_{\text {sust }, H}(t) w(t) d t
$$

ATR can be expressed in relative terms, where the ATR for one design is divided by that of a baseline design. This allows for easy comparison between aircraft. In Eq. 1, $H$ is the number of years of sustained operation for a particular aircraft design. $\Delta T_{\text {sust } H}$ is the global mean temperature change resulting from the operation of the given design, where emissions are assumed to be constant for the first $H$ years and zero thereafter. This temperature change is a function of the radiative forcing caused by the emission of a number of different pollutant species. The methods used to quantify the emissions of various pollutants are described in the following section.

There are multiple models available with varying levels of fidelity for calculating $\Delta T_{\text {sust, } H}$, and the current study uses the linear climate models and functions outlined by Dallara et al. in Ref. 8. One limitation on the models used to calculate the RFs for $\mathrm{NO}_{\mathrm{x}}$ and aviation induced cloudiness (AIC) is that they are based on data that only goes down to $16,500 \mathrm{ft}$. Below this altitude the effects of $\mathrm{NO}_{\mathrm{x}}$ and $\mathrm{AIC}$ are assumed constant. The RF effects for these emission species are quite small below this altitude, and the tiltrotor designs fly the bulk of the design mission above it, so the effects of this assumption should not be significant. For a lower-flying rotorcraft, such as a conventional helicopter, the assumption may have a greater impact on the results. 
The weighting function $w(t)$ allows discounting of temperature change effects in the years following $H$. This discounting is included so that long-term effects such as $\mathrm{CO}_{2}$ warming do not necessarily dominate ATR. $w(t)$ is defined in Eq. 2.

$$
w_{r}(t)= \begin{cases}1 & t \leq H \\ \frac{1}{(1 \square r)^{t-H}} & H \square t \leq t_{\max } \\ 0 & t_{\max } \square t\end{cases}
$$

The exponential decay of the weighting function in Eq. 2 is defined in terms of the discount rate, $r$. The rate of decay of the weighting function can be varied, and the effects of these variations will be shown in the results. A windowing function is also applied to ATR so that the metric only integrates effects over a specified length of time, $t_{\text {max }}$. This study uses a window length of 500 years. The operating lifetime $H$ is assumed to be 30 years.

\section{Quantifying Emissions}

Engine emissions can be quantified in terms of an emissions index (EI) that relates the amount of an emitted pollutant species to the amount of fuel burned. EI is generally expressed in either grams or kilograms of pollutant per kilogram of fuel burned. For some emission species, such as $\mathrm{CO}_{2}$ and water vapor, the EI is nearly constant, assuming ideal or near-ideal fuel combustion. For others, particularly $\mathrm{NO}_{x}$, the EI varies widely throughout the operating range of the engine. To calculate the ATR metric, the EIs need to be computed for several different species. The methods used for these calculations are described in the following sections.

\section{Constant EI Emissions}

For $\mathrm{CO}_{2}$, water vapor, sulfates $\left(\mathrm{SO}_{4}\right)$, and soot, the emissions indices are assumed to be constant. The values used for the constant EI emissions are contained in Table 1.

Table 1. Emissions indices for constant EI species ${ }^{33}$

\begin{tabular}{ll}
\hline Emission Species & Emissions Index \\
\hline $\mathrm{CO}_{2}$ & $3.16 \mathrm{~kg} \mathrm{CO} / \mathrm{kg}$ fuel \\
$\mathrm{H}_{2} \mathrm{O}$ & $1.26 \mathrm{~kg} \mathrm{H} \mathrm{O}_{2} \mathrm{O} / \mathrm{kg}$ fuel \\
$\mathrm{SO}_{4}$ & $2.0 \times 10^{-4} \mathrm{~kg} \mathrm{~S} / \mathrm{kg}$ fuel \\
$\mathrm{Soot}^{-5}$ & $4.0 \times 10^{-5} \mathrm{~kg} \mathrm{soot} / \mathrm{kg}$ fuel \\
\hline
\end{tabular}

\section{NO Emissions Index}

As shown in Fig. 2, oxides of nitrogen, including $\mathrm{NO}$ and $\mathrm{NO}_{2}$, and collectively called $\mathrm{NO}_{x}$, make a significant contribution to the environmental impact of aircraft. In order to calculate this impact, it is necessary to determine the emissions index of $\mathrm{NO}_{x}\left(\mathrm{EINO}_{\mathrm{x}}\right)$. Unlike the emissions indices for $\mathrm{CO}_{2}$ and water vapor, $\mathrm{EINO}_{x}$ depends on altitude (more specifically, ambient temperature and pressure), Mach number, and engine throttle setting. Additionally, because $\mathrm{EINO}_{\mathrm{x}}$ varies with the operating environment of the engine, it must be calculated for each phase of the design mission.

While there is a large amount of published turbofan $\mathrm{NO}_{x}$ emissions data and established methods for estimating variation with altitude, much of the data for the turboshaft engines used by existing rotorcraft is proprietary. ${ }^{34,35}$ To the authors' knowledge, there is no publicly available data that quantifies $\mathrm{NO}_{\mathrm{x}}$ emissions for specific turboshaft engines. There is a limited amount of data that has been collected by the Swiss Federal Office of Civil Aviation as part of their efforts to develop an emissions inventory for civil aviation. ${ }^{36}$ At the time of this writing, however, the only data released as part of that study relates $\mathrm{EINO}_{\mathrm{x}}$ to shaft horsepower, without identifying speed or altitude corrections, resulting in considerable uncertainty.

For the current study, estimates of $\mathrm{EINO}_{\mathrm{x}}$ are generated by using engine performance output from NDARC along with ICAO turbofan emissions data and the DLR fuel flow method described in Ref. 35. The steps used to generate the $\mathrm{NO}_{x}$ emissions index are described below: 
1. Obtain the fuel flow for each mission segment from the NDARC output.

2. Correct the fuel flow to sea level static conditions using the following equation:

$$
w_{\text {fuel,corr }}=w_{\text {fuel }} /\left(\delta_{M} \cdot \sqrt{\theta_{M}}\right)
$$

$w_{\text {fuel }}$ is the actual fuel flow, while $w_{\text {fuel,corr }}$ is the fuel flow corrected to sea level standard conditions. $\delta_{M}$ and $\theta_{M}$ are, respectively, the ratio of total pressure and temperature at the engine inlet to sea level static conditions.

3. Using a map of engine performance generated by NDARC, determine the power setting that matches the corrected sea level fuel flow.

4. Using a reference engine from the ICAO turbofan emissions databank, determine the corrected $\mathrm{NO}_{\mathrm{x}}$ emissions index for the given power setting.

5. Correct the emissions index back to flight conditions using the following equation:

$$
\mathrm{EINO}_{x} \square E I N O_{x, \text { corr }} \cdot \theta_{M}^{3} \cdot \delta_{M}^{0.4} \cdot F_{H}
$$

Here, $E I N O_{x}$ is the emissions index at flight conditions, and $E I N O_{x, \text { corr }}$ is the corrected emissions index determined in step 4. $F_{H}$ is a humidity correction factor given in Ref. 35.

Two different engines are used as references in step 4 of the above process. The GE CF34-3B and the Honeywell HTF7000 have fuel flows similar to what is calculated in NDARC for a turboshaft engine. Both engines are relatively modern, high bypass ratio, small turbofans. The HTF7000 and CF34 also represent the upper and lower bounds on $\mathrm{NO}_{\mathrm{x}}$ emissions for this category of engine, so they should bracket the expected quantity of $\mathrm{NO}_{\mathrm{x}}$ emissions for a turboshaft engine. ${ }^{34}$

There are two assumptions embedded in this method. First is that the variation of $\mathrm{EINO}_{\mathrm{x}}$ for a turboshaft is the same as that of a turbofan engine. Since both are gas turbine engines, employing the same thermal cycle, this assumption should be valid. The second assumption is that the RPTEM engine model implemented in NDARC is producing variations in fuel flow with speed and altitude in a manner consistent with the DLR fuel flow method. Since both the fuel flow method and the engine model in NDARC are based on real engine data, this assumption should be valid as well. Figure 6 shows the results of the $\mathrm{EINO}_{\mathrm{x}}$ calculations.

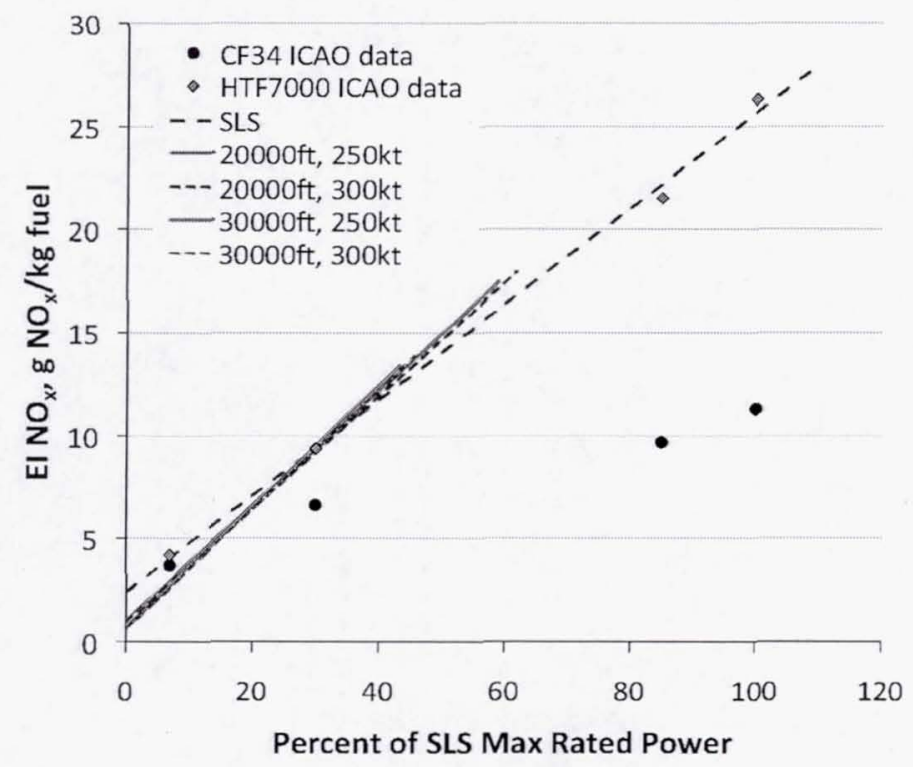

Figure 6. NOx emissions index for varied flight conditions and reference engine 
ICAO data for both the CF34-3B and HTF7000 engines is shown in Fig. 6. The green dotted line is a linear curve fit to the HTF7000 data, and is used as the SLS reference for the cruise conditions shown by the red and blue lines. The data for 20,000 and $30,000 \mathrm{ft}$ do not extend to $100 \%$, because only a fraction of the sea-level rated power is available at these altitudes. Compared to the differences between the $\mathrm{EINO}_{\mathrm{x}}$ values of the two reference engines, the speed and altitude corrections are relatively small. The effects of using different reference engine values for $\mathrm{EINO}_{\mathrm{x}}$ will be shown in the results section.

\section{Aviation Induced Cloudiness}

Also included in the calculation of the ATR metric is aviation induced cloudiness, which includes both contrails and aviation-induced cirrus clouds. Following the methodology of Ref. 8, the impact of AIC is assumed to be a function of cruise altitude and stage length, and does not account for changes in water vapor emissions or exhaust temperature. The consequence of this assumption is that for a given mission, the modeled RF due to AIC for a tiltrotor may be greatly overestimated. Since there is a high degree of uncertainty in radiative forcing due to AIC, as shown in Fig. 2, calculations of ATR are made both with and without its effects.

\section{Results}

Results for sweeps of wing loading and disk loading for a 27,000ft cruise altitude are presented in Figs. 7a and b for the 90 passenger tiltrotor. For this cruise altitude, minimum fuel burn, and therefore minimum $\mathrm{CO}_{2}$ production are achieved with a disk loading of $11 \mathrm{lb} / \mathrm{ft}^{2}$ and a wing loading of $95 \mathrm{lb} / \mathrm{ft}^{2}$, while the minimum empty weight design has a disk loading of $17 \mathrm{lb} / \mathrm{ft}^{2}$ and wing loading of $100 \mathrm{lb} / \mathrm{ft}^{2}$.

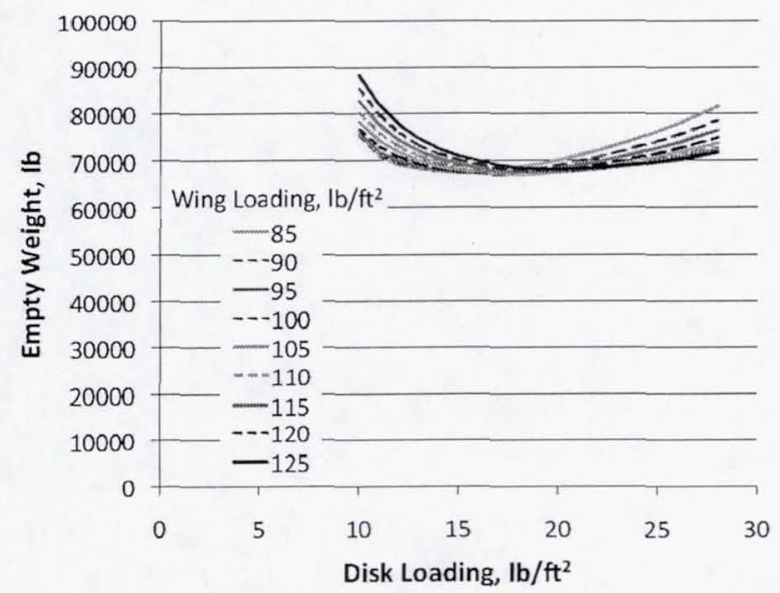

(a)

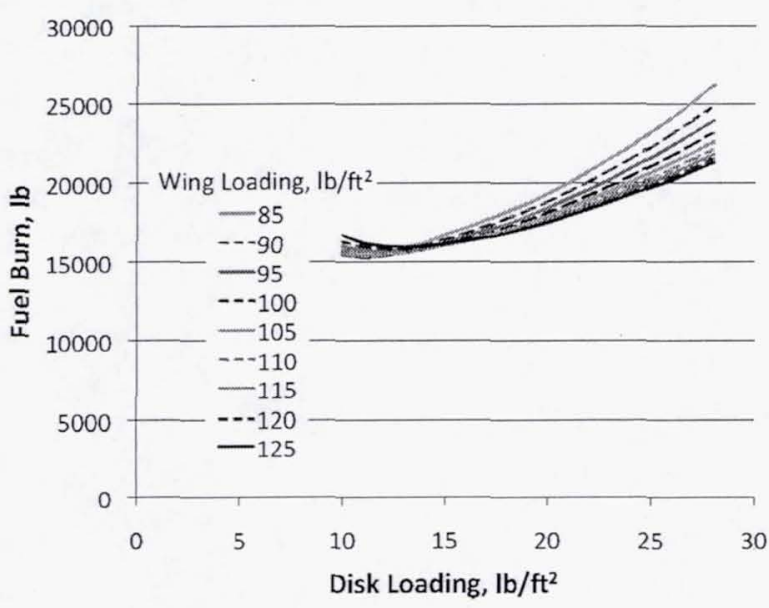

(b)

Figure 7. Empty weight and fuel burn vs. disk loading and wing loading for $27,000 \mathrm{ft}$ cruise altitude

Since the design mission cruise speed is $V_{b r}$, rather than a constant, the different wing loading and disk loading combinations result in small variations in cruise speed. As Fig. 6 shows, the sensitivity of $\mathrm{NO}_{\mathrm{x}}$ emissions to speed is not very large, so these small variations in cruise speed do not have a significant impact on $\mathrm{EINO}_{\mathrm{x}}$. Because the emissions index for $\mathrm{NO}_{\mathrm{x}}$ is nearly constant for the sweeps shown in Fig. 7, the minimum ATR is generally found at the same wing loading and disk loading combination as the minimum fuel burn for a given cruise altitude.

Cruise altitude was swept using a disk loading of $14 \mathrm{lb} / \mathrm{ft}^{2}$ and wing loading of $100 \mathrm{lb} / \mathrm{ft}^{2}$. The results are shown in Figs. $8 \mathrm{a}$ and b. For this combination of wing loading and disk loading, both the minimum fuel burn and minimum empty weight are achieved with a design cruise altitude of $31,000 \mathrm{ft}$. At this altitude, the engines are sized by both the OEI requirement and the $300 \mathrm{kt}$ cruise speed requirement. Below this altitude, the OEI requirement sizes the engines, while above it, the speed requirement is the determining factor, causing the abrupt change in slope in Fig. 8 a. 


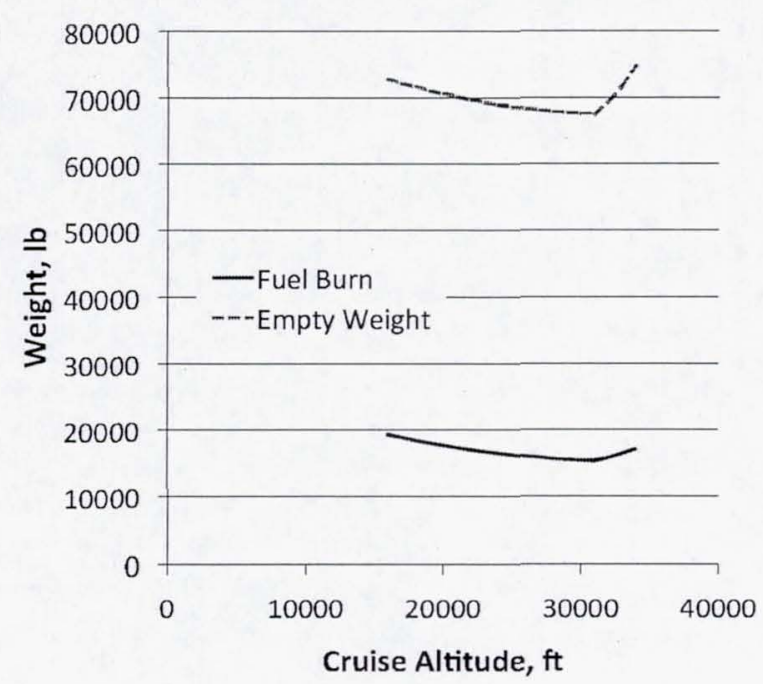

(a)

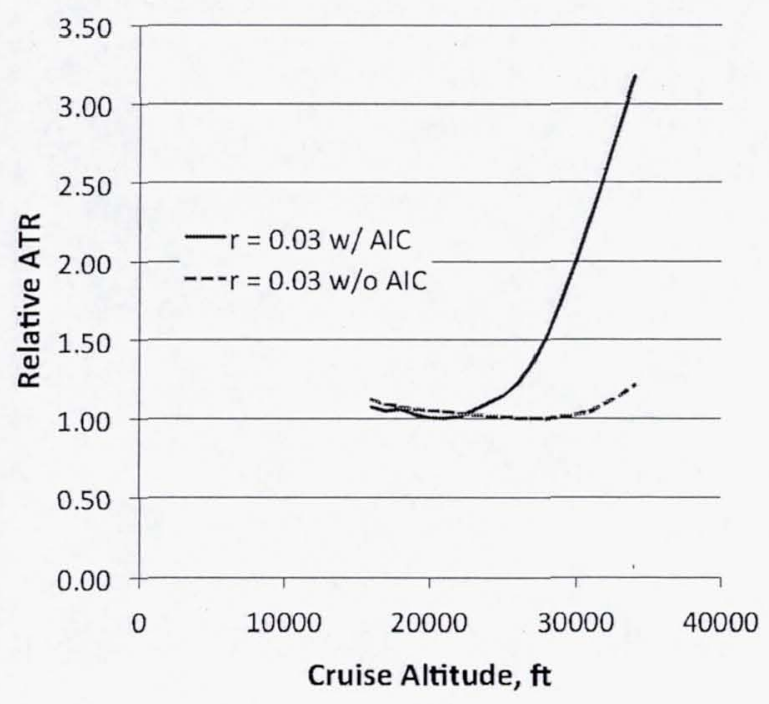

(b)

Figure 8. Empty weight, fuel burn, and relative ATR for varying cruise altitude

Figure $8 \mathrm{~b}$ shows how the ATR metric varies with changes in cruise altitude. Results are plotted both with and without aviation induced cloudiness for a discount rate of 0.03 using the $\mathrm{CF} 34$ as the reference engine for $\mathrm{NO}_{\mathrm{x}}$ emissions. Relative ATR is plotted here, where for each curve, the ATR values for all designs are divided by the value for the minimum ATR design, which has a relative ATR of 1 . When the effects of AIC are included, the minimum ATR design has a cruise altitude of 21,000 ft. If AIC effects are neglected, the minimum ATR design cruises at 27,000 ft. As previously stated, the computations assume that radiative forcing due to AIC is a function of only distance and altitude. Since the aircraft studied here is relatively small compared to typical passenger transports, the effects of AIC are likely overestimated by using this method. Also, strategies are currently being developed to reduce the effects of AIC by rerouting around areas in the atmosphere prone to aircraft contrails, so future aircraft may have significantly reduced climate impacts due to AIC. ${ }^{37}$

Both the discount rate used for computing ATR and the choice of reference engine for $\mathrm{NO}_{\mathrm{x}}$ emissions affect the results of the metric computations. Figures $9 \mathrm{a}$ and $\mathrm{b}$ show these effects without including AIC.

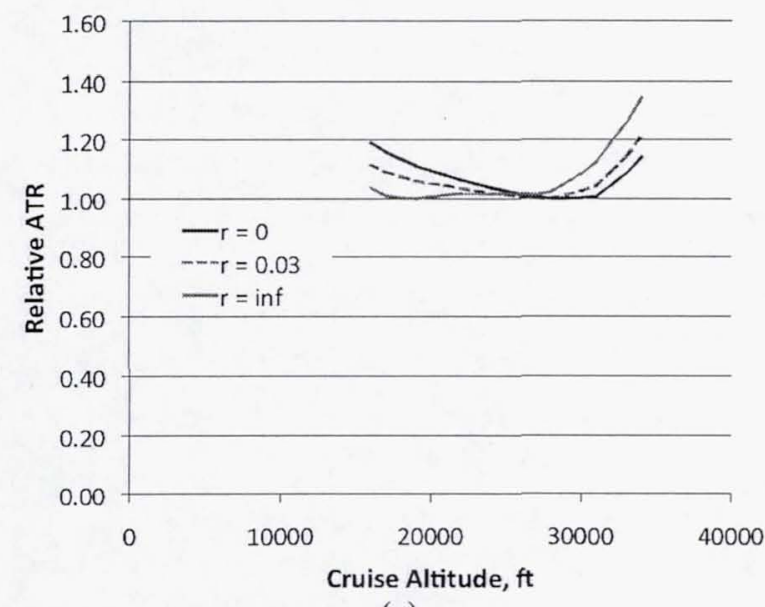

(a)

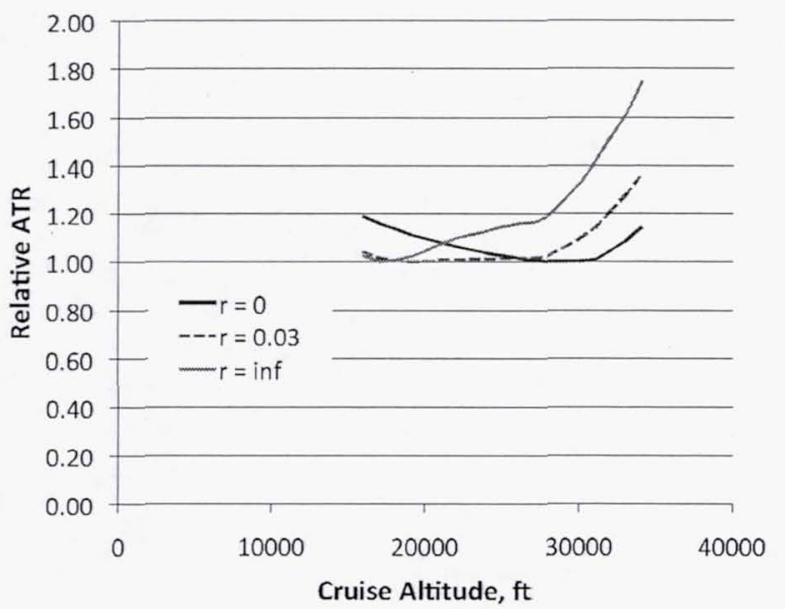

(b)

Figure 9. Altitude effects on ATR for varying discount rates and different reference engines for $\mathrm{NO}_{x}$ emissions: (a) CF34 and (b) HTF7000

The optimum cruise altitude for minimum ATR changes significantly with both discount rate and reference engine for $\mathrm{NO}_{\mathrm{x}}$ emissions. If there is no discounting of long-term effects $(r=0)$, the radiative forcing due to $\mathrm{CO}_{2}$ 
dominates the calculations, favoring a higher cruise altitude. If only short-term impacts are considered $(r=\mathrm{inf})$, then $\mathrm{NO}_{x}$ emissions have a much greater impact, and a lower cruise altitude results in decreased climate impact, despite increased fuel burn. The curves for ATR vs. cruise altitude can be very flat, as is the case for $r=0.03$ in Fig. $9 \mathrm{~b}$. The minimum for this curve occurs at $19,000 \mathrm{ft}$, but increasing the cruise altitude to $27,000 \mathrm{ft}$ only increases the relative ATR by $1.5 \%$ and decreases the fuel burn and empty weight by approximately $12 \%$ and $4 \%$, respectively. For this reason, as well as other design considerations, such as icing conditions at lower altitudes, targeting minimum ATR alone may not be an ideal design driver. The cruise altitudes for minimizing ATR are collected in Table 2.

Table 2. Discount rate and reference engine effects on cruise altitude for minimum ATR

\begin{tabular}{cll}
\hline Reference Engine & CF34-3B & HTF7000 \\
\hline$r=0$ & $28,000 \mathrm{ft}$ & $28,000 \mathrm{ft}$ \\
$r=0.03$ & $27,000 \mathrm{ft}$ & $19,000 \mathrm{ft}$ \\
$r=0.10$ & $27,000 \mathrm{ft}$ & $18,000 \mathrm{ft}$ \\
$r=$ inf & $19,000 \mathrm{ft}$ & $17,000 \mathrm{ft}$ \\
\hline
\end{tabular}

The conclusion drawn from Table 2 and Fig. 9 is that the impact on the final aircraft design of designing for minimum ATR depends heavily on the time horizon considered and the engine technology. In the case where longterm effects are included and lower- $\mathrm{NO}_{x}$ technology is assumed, ATR can be mostly minimized by designing for low fuel burn. If short-term effects are considered more important and a higher- $\mathrm{NO}_{\mathrm{x}}$ engine is assumed, designing for lower ATR results in a lower cruise altitude.

The choice of wing loading and disk loading for minimum fuel burn and empty weight is weakly affected by altitude. Figure 10 shows the results of a wing loading and disk loading sweep for a $20,000 \mathrm{ft}$ cruise altitude.

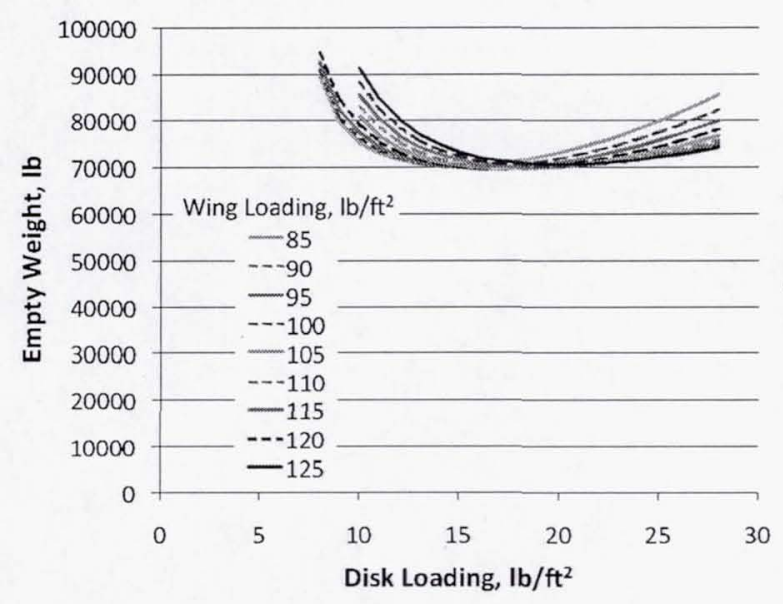

(a)

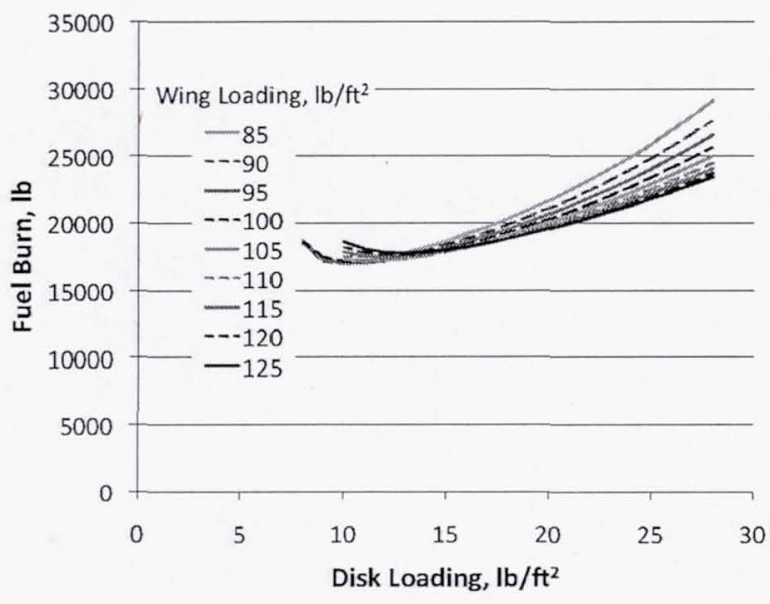

(b)

Figure 10. Empty weight and fuel burn vs. disk loading and wing loading for a 20,000 ft cruise altitude

Comparing Fig. 10 with Fig. 7 shows that the effect of cruise altitude on choosing a wing loading and disk loading for minimum empty weight and fuel burn is small. At $20,000 \mathrm{ft}$, minimum empty weight results from a disk loading of $17 \mathrm{lb} / \mathrm{ft}^{2}$ and a wing loading of $100 \mathrm{lb} / \mathrm{ft}^{2}$. Minimum fuel burn at this cruise altitude is achieved with a disk loading of $10 \mathrm{lb} / \mathrm{ft}^{2}$ and wing loading of $90 \mathrm{lb} / \mathrm{ft}^{2}$.

A summary of various tiltrotor designs is contained in Table 3. The first column can be considered a baseline design, where ATR is not minimized. All of the designs in Table 3 use a disk loading of $14 \mathrm{lb} / \mathrm{ft}^{2}$ and wing loading of $100 \mathrm{lb} / \mathrm{ft}^{2}$. The curves in Figs. 7 and 10 show that near their respective minima, the empty weight and fuel burn do not vary greatly with small changes in disk loading and wing loading, so this choice of baseline gives a good compromise between minimum fuel burn and empty weight. Designs using different methods for ATR calculation are shown to illustrate how the various methods of computing the ATR metric affect the final design. To compute the cost of ETS credits, a price of $\$ 8$ per metric tonne of $\mathrm{CO}_{2}$ is assumed, which is the approximate market price as of this writing. 
Table 3. Design summaries

\begin{tabular}{|c|c|c|c|c|c|}
\hline & $\begin{array}{l}\text { ATR not } \\
\text { considered }\end{array}$ & $\begin{array}{c}\text { Min ATR } \\
r=\inf \\
\text { HTF7000 } \mathrm{NO}_{\mathrm{x}}\end{array}$ & $\begin{array}{c}\text { Min ATR } \\
r=0.03 \\
\text { HTF7000 } \mathrm{NO}_{\mathrm{x}}\end{array}$ & $\begin{array}{c}\text { Min ATR } \\
r=0.03 \text { w/AIC } \\
\text { HTF7000 NO }\end{array}$ & $\begin{array}{c}\text { Min ATR } \\
r=0 \\
\text { CF34 NO }\end{array}$ \\
\hline Payload (90 pax), lb & 19,800 & 19,800 & 19,800 & 19,800 & 19,800 \\
\hline Rotor disk loading, $\mathrm{lb} / \mathrm{ft}^{2}$ & 14.0 & 14.0 & 14.0 & 14.0 & 14.0 \\
\hline Rotor solidity & 0.1148 & 0.1148 & 0.1148 & 0.1148 & 0.1148 \\
\hline Wing loading, $\mathrm{lb} / \mathrm{ft}^{2}$ & 100.0 & 100.0 & 100.0 & 100.0 & 100.0 \\
\hline Overall width, $\mathrm{ft}$ & 149.6 & 154.7 & 153.6 & 153.2 & 150.1 \\
\hline Rotor radius, $\mathrm{ft}$ & 34.4 & 35.7 & 35.4 & 35.3 & 34.5 \\
\hline Wing span, $\mathrm{ft}$ & 110.8 & 113.4 & 112.8 & 112.6 & 111.1 \\
\hline Cruise speed $\left(V_{b r}\right), \mathrm{kt}$ & 302.1 & 253.0 & 258.34 & 261.0 & 289.6 \\
\hline Cruise altitude, $\mathrm{ft}$ & 31,000 & 17,000 & 19,000 & 20,000 & 28,000 \\
\hline Empty weight, lb & 67,569 & 71,984 & 70,975 & 70,585 & 67,986 \\
\hline Max takeoff weight, $\mathrm{lb}$ & 119,772 & 128,875 & 126,784 & 125,978 & 120,632 \\
\hline Engine max rated power, hp & 6,844 & 7,364 & 7,245 & 7,199 & 6,893 \\
\hline Mission fuel, $\mathrm{lb}$ & 15,330 & 18,826 & 18,005 & 17,675 & 15,659 \\
\hline ETS credit cost per flight & $\$ 177$ & $\$ 215$ & $\$ 205$ & $\$ 202$ & $\$ 180$ \\
\hline
\end{tabular}

Depending on how ATR is computed, the resulting designs can be quite different. If a short time horizon is assumed with higher $\mathrm{NO}_{\mathrm{x}}$ emissions, a low cruise altitude with a slow cruise speed results in the smallest environmental impact, despite a $22 \%$ increase in fuel burn (and $\mathrm{CO}_{2}$ emissions) over the baseline given in column 1. The inclusion of AIC in the metric calculations also has a large impact on the design and favors a low cruise altitude. Decreasing the discount rate $r$ to place more importance on long-term emissions will favor a design that flies higher and faster, resulting in lower fuel burn and empty weight. If the lower $\mathrm{NO}_{\mathrm{x}}$-emitting reference engine is assumed and no discounting is applied, the resulting design is very similar to the baseline, with only a $2 \%$ increase in fuel burn and less than a $1 \%$ increase in empty weight.

\section{Future Work}

There are multiple avenues for follow-on studies to this work. A single design range and passenger capacity were assumed for the tiltrotor designs. If climate impact is normalized by seat-mile, varying the range and number of seats could produce interesting results. Other high-speed rotorcraft concepts, such as compound helicopters, are currently being studied for use as passenger transports. These concepts will be evaluated for their climate impact and compared to the civil tiltrotor results.

Similarly sized turboprop aircraft should also be evaluated. If the impacts of fixed-wing aircraft are compared with those of rotorcraft, there are additional environmental tradeoffs, such as noise and paved area for runways. These tradeoffs are well outside the scope of the metrics used for the current study, but are worth considering when comparing the different classes of aircraft.

\section{Conclusions}

This study examined the effect of designing a civil tiltrotor for both minimum cost and minimum environmental impact. Two climate impact metrics are computed to measure the emissions of a large civil tiltrotor-a simple $\mathrm{CO}_{2}$ based metric and a more complex radiative forcing-based metric designed to measure aviation impacts.

Designing independently for minimum empty weight, fuel burn, and climate impact results in distinctly different designs. When designing for minimal environmental impact using the Average Temperature Response metric, the choice of input parameters has a large effect on the resulting design. Different discount rates and the inclusion or exclusion of aviation induced cloudiness in the calculations yield widely varying results.

When aviation induced cloudiness is neglected, the choice of reference engine for $\mathrm{NO}_{\mathrm{x}}$ emissions changes the results as well. If a reference engine is chosen that has $\mathrm{NO}_{x}$ emissions towards the higher end of modern small turbofans, a lower cruise altitude and speed are desirable for minimizing climate impact. If lower $\mathrm{NO}_{\mathrm{x}}$ emission technology is selected for the reference engine, designing for low climate impact results in a higher cruise altitude and speed, and the design more closely resembles that for minimum fuel burn. This result suggests that for future tiltrotor designs with turboshaft engines, if the $\mathrm{NO}_{\mathrm{x}}$ emissions index is similar or lower than that of modern turbofans, designing for minimal fuel burn and $\mathrm{CO}_{2}$ emissions may be sufficient to minimize climate impact. In 
other words, with sufficiently advanced engine technology, the fuel burn penalty paid to minimize tiltrotor climate impact is small or non-existent.

\section{Acknowledgments}

The authors would like to acknowledge the assistance of Dr. Emily Schwartz Dallara, who developed the Average Temperature Response metric and provided helpful advice on its calculation.

\section{References}

${ }^{1}$ Couluris, G., Hange, C, Wardwell, D., Signor, D., and Phillips, J., "A Potential Impact Analysis of ESTOL Aircraft on Newark Airport Operations," American Institute of Aeronautics and Astronautics Modeling and Simulation Technologies Conference and Exhibit, Hilton Head, SC, August 20-23, 2007.

${ }^{2}$ Chung, W., Linse, D., Paris, A., Salvano, D., Trept, T., Wood, T., Gao, H., Miller, D., Wright, K., Young, R., and Cheng, V., "Modeling High-Speed Civil Tiltrotor Transports in the Next Generation Airspace," NASA/CR-2011-215960, October 2011.

${ }^{3}$ Johnson, W., Yamauchi, G., and Watts, M., "NASA Heavy Lift Rotorcraft Systems Investigation," NASA TP-2005-213467, December 2005.

${ }^{4}$ Russell, C. and Johnson, W., "Conceptual Design and Performance Analysis for a Large Civil Compound Helicopter," AHS Future Vertical Lift Aircraft Design Conference, San Francisco, CA, January 18-20, 2012.

${ }^{5}$ Acree, C.W. Jr., Yeo, H., and Sinsay, J., "Performance Optimization of the NASA Large Civil Tiltrotor," International Powered Lift Conference, London, UK, July 22-24, 2008.

${ }^{6}$ Acree, C. W., Jr., "Integration of Rotor Aerodynamic Optimization with the Conceptual Design of a Large Civil Tiltrotor," American Helicopter Society Aeromechanics Conference, San Francisco, CA, January 20-22, 2010.

${ }^{7}$ Lee, D.S. et al., "Aviation and Global Climate Change in the 21 ${ }^{\text {st }}$ Century," Atmospheric Environment, Vol. 43, No. 22-23, July 2009.

${ }^{8}$ Dallara, E. S., Kroo, I., and Waitz, I., "Metric for Comparing Lifetime Average Climate Impact of Aircraft," AIAA Journal, Vol. 49, No. 8, August 2011

9 Verlut, F. and Dyrla, N., "Definition by Eurocopter of a Green Metric to Assess Gas Emitted by Helicopters in Operation," American Helicopter Society 36th European Rotorcraft Forum, Paris, France, September 6-9, 2011.

${ }^{10}$ Fuglestvedt, J. S., Berntsen, T., Godal, O., Sausen, R., Shine, K. P., and Skodvin, T., "Metrics of Climate Change: Assessing Radiative Forcing and Emission Indices," Climatic Change, Vol. 68, No. 3, 2003, pp. 267-331.

${ }^{11}$ Sausen, R. et al., "Aviation Radiative Forcing in 2000: An Update on IPCC (1999)," Meteorologische Zeitschrift, Vol. 14,

No. 4, August 2005 .

12 Köhler, M. O., Rädel, G., Dessens, O., Shine, K. P., Rogers, H. L., Wild, O., and Pyle, J. A., "Impact of Perturbations to

Nitrogen Oxide Emissions from Global Aviation," Journal of Geophysical Research, Vol. 113, 2008, Paper D11305.

${ }^{13}$ Ellerman, D. and Buchner, B., "The European Union Emissions Trading Scheme: Origins, Allocation, and Early Results," Review of Environmental Economics and Policy, Vol. 1, No. 1, Winter 2007.

${ }^{14}$ van Hasselt, M., van der Zwan, F., Ghijs, S., and Santema, S., "Developing a Strategic Framework for an Airline dealing with the EU Emission Trading Scheme," $9^{\text {th }}$ AIAA A viation Technology, Integration, and Operations Conference (ATIO), Hilton Head, South Carolina, September 2009.

${ }^{15}$ Kennedy, D. et al, "Meeting Carbon Budgets - The Need for a Step Change," Progress report to Parliament Committee on Climate Change, October 12, 2009.

16 "Questions and Answers on the Commission's Proposal to Revise the EU Emissions Trading System," MEMO/08/35, Brussels, January 23, 2008, Available at http://europa.eu/rapid/pressReleasesAction.do? reference=MEMO/08/35, (retrieved November 2011)

${ }^{17}$ Intergovernmental Panel on Climate Change, Climate Change 2007 - The Physical Science Basis, Contribution of Working Group I to the Fourth Assessment Report of the Intergovernmental Panel on Climate Change, 2007, Cambridge Univ. Press, Cambridge, U.K., 2007.

${ }^{18}$ Lee, D.S. et al, "Incorporating Aviation $\mathrm{NO}_{\mathrm{x}}$ Impacts into Policy Using Climate Metrics," IPCC Expert Meeting on the Science of Alternative Metrics, Oslo, Norway, March 2009.

${ }^{19}$ Johnson, W. "NDARC. NASA Design and Analysis of Rotorcraft." NASA TP 2009-215402, December 2009

${ }^{20}$ Johnson, W. "NDARC — NASA Design and Analysis of Rotorcraft. Theoretical Basis and Architecture." American Helicopter Society Specialists' Conference on Aeromechanics, San Francisco, CA, January 2010.

${ }^{21}$ Johnson, W. "NDARC - NASA Design and Analysis of Rotorcraft. Validation and Demonstration." American Helicopter Society Specialists' Conference on Aeromechanics, San Francisco, CA, January 2010.

${ }^{22}$ Johnson, W., "Technology Drivers in the Development of CAMRAD II," American Helicopter Society Aeromechanics Specialist Meeting, San Francisco, California, January 1994.

${ }^{23}$ Johnson, W. "Rotorcraft Aeromechanics Applications of a Comprehensive Analysis." HeliJapan 1998: AHS International Meeting on Rotorcraft Technology and Disaster Relief, Gifu, Japan, April 1998.

${ }^{24}$ Johnson, W. "Rotorcraft Aerodynamic Models for a Comprehensive Analysis." American Helicopter Society 54th Annual Forum, Washington, D.C., May 1998. 
${ }^{25}$ Johnson, W. "Calculation of Tilt Rotor Aeroacoustic Model (TRAM DNW) Performance, Airloads, and Structural Loads." American Helicopter Society Aeromechanics Specialists' Meeting, Atlanta, GA, November 2000.

${ }^{26}$ Yeo, H. "Calculation of Rotor Performance and Loads Under Stalled Conditions." American Helicopter Society 59th Annual Forum, Phoenix, AZ, May 2003.

${ }^{27}$ Yeo, H., Bousman, W. G., and Johnson, W., "Performance Analysis of a Utility Helicopter with Standard and Advanced Rotor," Journal of the American Helicopter Society, Vol. 49, No. 3, July 2004.

${ }^{28}$ Yeo, H., and Johnson, W., "Assessment of Comprehensive Analysis Calculation of Airloads on Helicopter Rotors," Journal of Aircraft, Vol. 42, No. 5, Sept.-Oct. 2005.

${ }^{29}$ Yeo, H., and Johnson, W., "Prediction of Rotor Structural Loads with Comprehensive Analysis," Journal of the American Helicopter Society, Vol. 53, No. 2, April 2008.

${ }^{30}$ Harris, F.D. "Rotor Performance at High Advance Ratio; Theory versus Test." NASA CR 2008-215370, October 2008.

${ }^{31}$ Hess, R.W. and Romanoff, H. P., "Aircraft Airframe Cost Estimating Relationships," The RAND Corporation, Santa Monica, CA, December 1987, R-3255-AF.

${ }^{32}$ Morrison, J., Bonnefoy, P., Hansman, R. J., and Sgouridis, S., "Investigation of the Impacts of Effective Fuel Cost Increase on the US Air Transportation Network and Fleet," 10th AIAA Aviation Technology, Integration, and Operations (ATIO) Conference, Fort Worth, TX, September 13-15, 2010.

33 Intergovernmental Panel on Climate Change, Aviation and the Global Atmosphere, Cambridge University Press, Cambridge, UK, 1999.

34 ICAO Aircraft Emissions Databank, available at http://easa.europa.eu/environment/edb/aircraft-engineemissions.php, accessed June 2012.

35 Deidewig, F., Döpelheuer, A., and Lecht, M., "Methods to Assess Aircraft Engine Emissions in Flight," 20 th International Council on Aeronautical Sciences Congress, Sorrento, Italy, 1996.

36 Rindlisbacher, T. "Guidance on the Determination of Helicopter Emissions," Swiss Confederation Federal Office of Civil Aviation (FOCA), Ref. 0 / 3/33/33-05-20, Bern, Switzerland, March, 2009

37 Chen, N., Sridhar, B., and Ng, H., "Tradeoff Between Contrail Reduction and Emissions in United States National Airspace," Journal of Aircraft, Vol. 49, No. 5, Sept.-Oct. 2012. 